\title{
Teaching and Learning Guide: Towards a Cultural-Clinical Psychology
}

\author{
Andrew G. Ryder ${ }^{1,2}$ and Yulia E. Chentsova-Dutton, ${ }^{3}$ \\ ${ }^{1}$ Concordia University \\ ${ }^{2}$ Jewish General Hospital \\ ${ }^{3}$ Georgetown University
}

\section{Authors' Introduction}

The study of culture and mental health is an interdisciplinary endeavor with a long history, but psychology has only been fitfully involved with the ongoing conversation. Cultural psychiatry, by contrast, represents a decades-long interdisciplinary endeavor primarily involving psychiatrists and anthropologists. One problem is that the anthropological view of culture, not as independent variable but as deep context, has been unfamiliar to psychologists until relatively recently. Although anthropological views have influenced researchers in cultural psychology, at times profoundly, collaborations between cultural and clinical psychologists remain uncommon.

Our paper in Social and Personality Psychology Compass describes one way of thinking about how cultural psychology and clinical psychology might be integrated, to the mutual benefit of both disciplines. We advocate a psychological approach to culture and mental health that goes beyond simply stating that 'culture matters', hoping to go beyond descriptions of group differences to an exploration of the processes by which cultural context shapes health and well-being. Ideally, the emerging discipline combines the strengths of cultural psychology and clinical psychology, drawing on the theories, methodologies, and empirical literatures of both.

Indeed, in many ways, cultural-clinical psychology is not new. Psychologists have conducted research on culture and mental health for decades, and we draw on this work extensively in describing our approach. Nonetheless, the specific integration of cultural and clinical psychology is just beginning to emerge as an organized field of study. This teaching and learning guide includes some current work in this field, but emphasizes the various contributions that have shaped our view of what cultural-clinical psychology might become.

Correspondence: Department of Psychology, Concordia University, 7141 Sherbrooke St. W. (PY139-3), Montreal, Quebec, H4B 1R6, Canada. Email: andrew.ryder@concordia.ca
Most of the resources listed here draw from longestablished disciplines that have contributed to cultural-clinical psychology: cultural, cross-cultural, and multicultural psychology; cultural psychiatry; and medical anthropology. Regardless of theoretical perspective or specific content, our selection is guided by the search for a common starting point for interested scholars. Those interested in specific cultural settings or clinical phenomena would then be able to pursue these topics through focused literature searches. Note that a version of this guide, updated on an ongoing basis to reflect new developments in the field, is available at culturalclinicalpsych.org.

\section{Recommended Readings}

We have selected ten theoretical and ten empirical papers to provide a general introduction to cultural-clinical psychology, plus the four studies that were considered in some detail in our original article. In selecting these papers, we opted for a mixture of (a) older and newer contributions; (b) junior and senior scholars; and (c) psychology and other disciplines. We tried to select papers where the highlighted scholars are the primary authors; interested readers could conduct literature searches on any of these authors and find many additional relevant readings. As well, we focused on journal articles rather than book chapters to make it easier for universitybased readers to quickly access the recommended readings online. Finally, both the individual readings and the whole set were selected primarily with the beginner in mind -our original article plus these recommendations comprises a set of 25 papers that will give an overview of the ideas, research methods, findings, and thinkers who are helping to shape this field.

\section{Conceptual Underpinnings}

Cheung, F. M., van de Vijver, F. J. R., \& Leong, F. T. L. (2011). Toward a new approach to the study of personality in culture. American Psychologist, 66, 593-603.

Fanny Cheung (Chinese University of Hong Kong) is a clinical psychologist who takes a cross-cultural psychology 
perspective on assessment of personality and psychopathology, especially in Chinese contexts. Fons van de Vijver (Tilburg University) is a cross-cultural psychologist who has written widely on quantitative methods and assessment for cross-cultural research. Frederick Leong (Michigan State University) is the director of the Consortium for Multicultural Psychology Research, integrating a multicultural perspective with clinical and counseling psychology. This review promotes a 'combined emic -etic' approach to designing culturally appropriate instruments to assess personality and psychopathology, using examples from Chinese and South African contexts.

Draguns, J. G., \& Tanaka-Matsumi, J. (2003). Assessment of psychopathology across and within cultures: Issues and findings. Behaviour Research and Therapy, 41, 755-776.

Juris Draguns (The Pennsylvania State University) and Junko Tanaka-Matsumi (Kwansei Gakuin University) study clinical psychology issues from a cross-cultural psychology perspective. Here, they present an evidence-based review of cultural issues in the assessment of psychopathology. They advocate greater attention to cultural values in explaining group differences, and draw the reader's attention to the potential impact of the diagnostician's cultural context and of rapid social change.

Hall, G. C. N. (2001). Psychotherapy research with ethnic minorities: Empirical, ethical, and conceptual issues. Journal of Consulting and Clinical Psychology, 69, 502-510.

Gordon Nagayama Hall (University of Oregon) counseling and ethnic/counseling and ethnicminority psychology perspectives. This paper explores the lack of firm evidence for Empirically Supported Therapies (ESTs) in ethnic minority groups, and the similar lack for specially designed $\mathrm{Cul}-$ turally Sensitive Therapies (CSTs). The gap between these two goals is attributed to differences in theories and methods in the two research communities, and the lack of dialogue between them.

Kirmayer, L. J. (2007). Psychotherapy and the cultural concept of the person. Transcultural Psychiatry, 44, 232-257.

Laurence Kirmayer (McGill University) is a cultural psychiatrist and director of the Division of Social and Transcultural Psychiatry at McGill University (see section 3). This paper argues that psychotherapies are unique in that they involve explicit talk about the self, which is based on implicit self-concepts, which are shaped by culture. He describes several different culturally shaped models of the self and discusses their psychological ramifications. These approaches to self are contrasted with the 'idiocentric' or individualist model grounding most 'Western' assumptions about psychotherapy.

Kleinman, A. M. (1977). Depression, somatization, and the new cross-cultural psychiatry. Social Science and Medicine, 11, 3-10.
Arthur Kleinman (Harvard University) is a psychiatrist with anthropological training who launched the modern field of cultural psychiatry with this paper. He uses the example of the somatization of depression in Taiwan to illustrate how culture shapes mental health. Moreover, he argues that it is this attention to shaping that should be the hallmark of the new field, rather than a focus on group differences. Over the ensuing decades, several authors have commented on the progress made with this endeavor.

Lau, A. S., Chang, D. F., \& Okazaki, S. (2010). Methodological challenges in treatment outcome research with ethnic minorities. Cultural Diversity and Ethnic Minority Psychology, 16, 573-580.

Anna Lau (University of California, Los Angeles), Doris Chang (New School for Social Research), and Sumie Okazaki (New York University) are clinical psychologists who conduct research in East Asian and Asian American cultural settings. This paper reviews the challenges that face researchers attempting to conduct ethnoculturally diverse treatment outcome studies. They begin by considering the limitations of the Randomized Clinical Trial approach, and then propose several alternatives aimed at advancing culturally focused treatment research.

Lee, S. (1996). Cultures in psychiatric nosology: The CCMD-2-R and international classification of mental disorders. Culture, Medicine and Psychiatry, 20, 421-472.

Sing Lee (Chinese University of Hong Kong) is a psychiatrist with particular research and clinical interests in eating and somatoform disorders. This paper takes the perspective that psychiatric symptoms and syndromes are shaped by cultural context, a process that is evident in the construction of formal diagnostic systems. These systems both reflect and constrain the ways in which psychopathology is experienced, expressed, and communicated to others. The argument is made through a detailed consideration of the revised second edition of the Chinese psychiatric classification system.

Littlewood, R. (1990). From categories to contexts: A decade of the "New cross-cultural Psychiatry". British Journal of Psychiatry, 156, 308-327.

Roland Littlewood (University College, London) is trained as both a psychiatrist and anthropologist and applies ethnographic methods to the study of mental health, with a particular interest in religion. This paper critically examines the progress made in cultural psychiatry since Kleinman's 1977 paper, in particular the move from labeled cultural categories to fluid cultural contexts.

López, S., \& Guarnaccia, P. J. (2000). Cultural psychopathology: Uncovering the social world of mental illness. Annual Review of Psychology, 51, 571-598.

Steven López (University of Southern California) and Peter Guarnaccia (Rutgers University) are, respectively, a clinical psychologist and a cultural anthropologist who both have a particular interest in Latino mental health. This review 
emphasizes developments in the field since Kleinman's Rethinking Psychiatry from 1988, covering theoretical (defining culture, purposes of cultural research, culture in DSM) and empirical (anxiety, schizophrenia, childhood disorders) topics. The paper concludes by considering a few emerging trends for future research in the area.

Sue, S., \& Zane, N. (1987). The role of culture and cultural techniques in psychotherapy: A critique and reformulation. American Psychologist, 42, 37-45.

Stanley Sue and Nolan Zane (both at University of California, Davis) are clinical psychologists with particular interests in Asian American mental health; Dr. Zane directs the Asian American Center on Disparities Research. Here, the authors critique the emphasis on cultural match and specific cultural knowledge, advocating instead for more general principles. They argue that these principles are grounded in good psychotherapy practice regardless of the cultural issues, but are especially important when engaging with clients across a cultural divide.

\section{Exemplary Studies}

Gone, J. P. (2009). A community-based treatment for Native American historical trauma: Prospects for evidencebased practice. Journal of Consulting and Clinical Psychology, 77, 751-762.

Joseph Gone (University of Michigan) is a clinical psychologist who focuses on the mental health of indigenous peoples. This study takes a mixed-methods approach, combing qualitative and quantitative techniques. Specifically, it demonstrates how semi-structured interviews combined with thematic content analysis can be used to generate rich data about a culturally specific treatment setting. In addition to presenting specific results, the paper presents a vision of how the gap between evidence-based treatment and culturally sensitive therapies might be bridged.

Griner, D., \& Smith, T. B. (2006). Culturally adapted mental health intervention: A metaanalytic review. Psychotherapy: Theory, Research, Practice, Training, 43, 531-548.

Timothy Smith (Brigham Young University) is a counseling psychologist interested in how culture, ethnicity/race, and religion/spirituality impact on counseling and psychotherapy. Together with his students he has published several meta-analyses on the effectiveness of matching -for example, ethnic or religious matching -on therapy outcomes. In this example, the authors evaluated 76 studies conducted in the United States and found an advantage for those therapies specifically adapted for, and used with, a single ethnic group. A somewhat smaller advantage was also found when the therapist used the client's first language rather than English.

Hinton, D. E., Chhean, D., Pich, V., Um, K., Fama, J. M., \& Pollack, M. H. (2006). Neck-focused panic attacks among Cambodian refugees: A logistic and linear regression analysis. Journal of Anxiety Disorders, 20, 119-138.

Devon Hinton (Harvard University) is a cultural psychiatrist interested in how culture shapes anxiety disorders, especially panic disorder and PTSD. His research has demonstrated how just as American cultural beliefs surrounding heart attacks contribute to the catastrophic misinterpretation of chest pain, and hence to a loop that culminates in a panic attack, a similar pattern can be observed for Cambodians with neck pain. This study uses regression methods to study the influence of mind-level factors on a culturally shaped symptom presentation and also uses mediation and moderation to help explain differences between patients with and without neck-focused panic attacks.

Jenkins, J. H. (1997). Subjective experience of persistent schizophrenia and depression among US Latinos and EuroAmericans. British Journal of Psychiatry, 171, 20-25.

Janis Jenkins (University of California, San Diego) is an anthropologist interested in the subjective experiences of patients with different psychiatric disorders, living in different cultural contexts. This study used structured and semistructured interview methods to yield both qualitative and quantitative data. Strikingly, nearly half the overall sample did not mention the illness when describing their life situation in detail -their scripts for describing distress focused much more on whether or not one was living a good and desirable life rather than incorporating psychiatric labels. This study demonstrates how mixed methods can be used to uncover cultural scripts.

Kim, H. S., Sherman, D. K., Sasaki, J. Y., Xu, J., Chu, T. Q., Ryu, C., Suh, E. M., Graham, K., \& Taylor, S. E. (2010). Culture, distress, and oxytocin receptor polymorphism (OXTR) interact to influence emotional support seeking. Proceedings of the National Academy of Sciences, 107, 15717-15721.

Heejung Kim (University of California, Santa Barbara) is a cultural psychologist interested in how culture shapes basic psychological processes. This collaborative interdisciplinary study is one of the few to integrate culture, mind, and brain in the same design. Here, brain is represented by a genetic polymorphism that affects oxytocin receptors. The research team found that neither genetic/brain variation nor cultural variation is sufficient to explain a clinically important phenomenon at the mind level; namely, emotional support seeking from important others.

Kohrt, B. A. (2008). "Somatization" and "Comorbidity": A study of Jhum-Jhum and depression in rural Nepal. Ethos, 33, 125-147.

Brandon Kohrt (Duke University) has doctoral degrees in medicine and anthropology, and combines both disciplines in his work, much of which has been conducted in Nepal. His research uses a range of methods, both qualitative and quantitative, including ethnography, medical examinations, psy- 
chophysiological measurement, and subjective self-report. In this study, he shows that Nepalese patients with symptoms consistent with 'somatization' are also much more likely to have physical conditions that could account for these somatic symptoms. The study highlights the importance of considering both physical and psychological causation.

Mauss, I. B., Butler, E. A., Roberts, N. A., \& Chu, A. (2010). Emotion control values and responding to an anger provocation in Asian-American and European-American individuals. Cognition $\mathcal{E}$ Emotion, 24, 1026-1043.

Iris Mauss (University of California, Berkeley), Emily Butler (University of Arizona), and Nicole Roberts (Arizona State University) are research psychologists in affective science interested in the cultural shaping of emotional response. This paper shows how an in vivo lab experience can be used to study anger response, as measured by physiology, behavioral observation, and subjective self-report. Importantly, patterns of cultural variation depended on the assessment method used; observed differences were partially mediated by the extent to which participants valued emotional control.

Tsai, J. L., Miao, F. F., \& Seppala, E. (2007). Good feelings in Christianity and Buddhism: Religious differences in ideal affect. Personality and Social Psychology Bulletin, 33, 409-421.

Jeanne Tsai (Stanford University) is a clinical psychologist and affective scientist who takes a cultural psychology perspective on emotions and emotional disorders. In this study, cultural contexts are extended to their religious manifestations. Importantly, culture is considered both as 'in the head' and 'in the world', with one study based on subjective self-report and the second and third based on analysis of sacred texts and contemporary religious texts, respectively. This paper demonstrates how a single line of research can assess culture in multiple ways.

Weisz, J. R., Weiss, B., Suwanlert, S., \& Chaiyasit, W. (2006). Culture and youth psychopathology: Testing the syndromal sensitivity model in Thai and American adolescents. Journal of Consulting and Clinical Psychology, 74, 1098-1107.

John Weisz (Harvard University) is a clinical psychologist whose extensive research on child and adolescent psychopathology includes several cultural studies. Bahr Weiss (Vanderbilt University) is a clinical psychologist interested in how culture shapes symptom expression in children. This study tests the Syndromal Sensitivity Model, which posits three processes linking culture and symptom presentation, in Thai and American youth samples. Results confirmed previously identified Thai-specific syndromes, demonstrating how cultural processes shape them in predictable ways.

Williams, C. C. (2003). Re-reading the IPSS research record. Social Science and Medicine, 56, 501-515.

Charmaine Williams (University of Toronto) is a pro- fessor of Social Work who focuses on race, culture, and disability in psychiatric settings. This study starts with the International Pilot Study of Schizophrenia and its finding, well-known to cultural psychiatrists, that outcomes are significantly better in 'the Third World' as compared with 'the Western World'. She uses a qualitative method, discourse analysis, to critically examine the literature that followed publication of these findings, demonstrating that much of the resulting discourse served to maintain assumptions of 'Western' superiority.

\section{Focal Studies from the Social and Personality Psychology Compass Paper}

Ban, L., Kashima, Y., \& Haslam, N. (2012). Does understanding behaviour make it seem normal? Perceptions of abnormality among Euro-Australians and ChineseSingaporeans. Journal of Cross-Cultural Psychology, 43, 286-298.

This study examines cultural variation in beliefs about mental illness; specifically, whether a clear causal explanation makes abnormal behavior appear more normal and acceptable. While psychological explanations made behavior seem more normal to Euro-Australian students, they actually made the same behavior seem less normal to ChineseSingaporean students. Chinese-Singaporeans had a greater tendency to prefer moral explanations of abnormal behavior, a group difference partially mediated by a measure of 'traditionalism'. The study highlights the potential influence of intersubjectively held beliefs about abnormal behavior and how group differences can be partially unpacked through cultural values.

Chentsova-Dutton, Y. E., Chu, J. P., Tsai, J. L., Rottenberg, J., Gross, J., \& Gotlib, I. H. (2007). Depression and emotional reactivity: Variation among Asian Americans of East Asian descent and European Americans. Journal of Abnormal Psychology, 116, 776-785.

Chentsova-Dutton, Y. E., Tsai, J. L., \& Gotlib, I. H. (2010). Further evidence for the cultural norm hypothesis: Positive emotion in depressed and control European Americans and Asian Americans. Cultural Diversity and Ethnic Minority Psychology, 16, 284-295.

These studies involve four-group quasi-experiment comparing depressed and non-depressed East Asian and European Americans. The researchers used a multi-method approach, with psychophysiological, facial coding, and subjective self-report measurements of emotional response to film clips. Results were consistent with the Cultural Norm Hypothesis, that depression involves a deviation from cultural norms regarding emotions. These studies demonstrate how well-known and putatively universal findings on mental health do not necessarily hold in other cultural contexts. At the same time, they demonstrate how more general hypotheses that incorporate cultural norms can help explain observed 
cross-group differences.

Ryder, A. G., Yang, J., Zhu, X., Yao, S., Yi, J., Heine, S. J., \& Bagby, R. M. (2008). The cultural shaping of depression: Somatic symptoms in China, psychological symptoms in North America. Journal of Abnormal Psychology, 117, 300-313.

This study uses multiple clinical assessment approaches-clinical interview, structured interview, and questionnaire-to evaluate symptom differences in Chinese and Euro-Canadian depressed patients. This study outlines a method for cross-group comparisons that point to potential specific explanations. First, item and structural equivalence methods are used to establish that the same symptom measures can be used across contexts and languages. Then, once group differences are established, mediation analysis is used to show how group differences in somatic symptom presentation can be partially explained by a tendency to engage in 'externally-oriented thinking.'

\section{On the Bookshelf}

Bhugra, D., \& Bhui, K. (Eds.) (2007). Textbook of Cultural Psychiatry. Cambridge: Cambridge University Press.

Dinesh Bhugra (King's College, University of London) and Kamaldeep Bhui (Queen Mary University of London) are cultural psychiatrists who collaborated on editing a textbook in this field. Chapters 1,2, 8, and 10-12 are particularly useful for background theory, 15-25 for specific disorders, and 28, 31, and 32 for psychological treatment.

Heine, S. J. (2011). Cultural Psychology (2nd edn). New York: Norton.

Steven Heine (University of British Columbia) is a cultural psychologist who has written the first textbook for this specific approach to culture and psychology. Aimed at senior undergraduates and beginning graduate students, it introduces readers to the full range of the field, including chapters 11 and 12 on physical and mental health.

Kitayama, S., \& Cohen, D. (2010). Handbook of Cultural Psychology. New York: Guilford Press.

Shinobu Kitayama (University of Michigan) and Dov Cohen (University of Illinois at Urbana-Champaign) are cultural psychologists who have edited the first comprehensive handbook covering this perspective. In particular, Hazel Markus (Stanford University), a major figure in launching contemporary cultural psychology in the early 1990s, contributes an introduction to 'sociocultural psychology' is provided by. Also, Anthony Marsella (University of Hawai'i at Manoa), a pioneer in the integration of clinical and crosscultural psychology, contributes a chapter on culture and psychopathology.

Kleinman, A. (1991). Rethinking Psychiatry: From Cultural Category to Personal Experience. New York: Simon and Schuster.
Arthur Kleinman's (see above) book-length introduction to cultural psychology remains essential after more than two decades. Chapters 1 to 4 are particularly relevant to culturalclinical psychology.

Littlewood, R., \& Dein, S. (2000). Cultural Psychiatry and Medical Anthropology: An Introduction and Reader. London: Athlone Press. This volume by Roland Littlewood (see above) and Simon Dein (University College London; an anthropologist/psychiatrist interested in culture, religion, and mental health) brings together a selection of classic papers in cultural psychiatry and medical anthropology. George Miller Beard's 1880 paper on the 'Jumping Frenchmen of Maine' opens the book, followed by contributions from scholars such as Emil Kraepelin, Ernest Jones, Marcel Mauss, Claude-Lévi Strauss, and George Devereux, among others, and concluding with Henry Murphy's 1971 paper on the evolution of Latah and Amok.

Tseng,W.-S. (2003). Clinician's Guide to Cultural Psychiatry. San Diego, CA: Academic Press.

Wen-Shing Tseng (University of Hawai'i at Manoa) is a cultural psychiatrist who distilled his earlier textbook for the field into this guide written especially for clinicians. Chapters 1-4 are recommended for a general theoretical overview, whereas chapters 5-7 serve as practical guides to culturally competent practice.

\section{Resources Available Online}

Afflictions (www.afflictionsfilmseries.com). Anthropologist and filmmaker Robert Lemelson directs this six-film series about mental illness in Indonesia

The Americanization of Mental Illness (www.nytimes. com/2010/01/10/magazine/10psyche-t.html). Author and journalist Ethan Watters argues in this New York Times Magazine article that the assumption that Americanmental health norms are universal contributes not just to misunderstandings, but to shaping how distress is experienced and expressed in other cultural contexts. His popular science book Crazy Like Us explores this argument in more detail (crazylikeus.com).

Cultural-Clinical Psychology (culturalclinicalpsych.org). A regularly updated collection of online resources organized by a network of research psychologists who work at the interface of cultural and clinical psychology. Resources include an expanded and occasionally updated version of this teaching and learning guide, and links to a Frontiers in Cultural Psychology research topic (www.frontiersin.org/ cultural_psychology): "Contextual shaping of health and well-being: Contributions from cultural-clinical psychology".

Culture and Mind: Psychiatry's Missing Diagnosis (vedantam.com/culture-and-mind-series-2005.html). Shankar Vedantam, science correspondent for National Public Radio, originally published this three-part series in the 
Washington Post. In discussion with cultural psychiatrists, along with some critics, he provides an overview of some provocative findings that challenge the standard medical model of mental illness.

Division 45 of the American Psychological Association (division45.org). Division 45 of the APA, the Society for the Psychology Study of Ethnic Minority Issues, promotes psychological research on ethnic minorities in the United States. The division coordinates the journal Cultural Diversity and Ethnic Minority Psychology (www.apa.org/pubs/ journals/cdp/index.aspx).

Division of Social and Transcultural Psychiatry, McGill University (www.mcgill.ca/tcpsych).

This long-established interdisciplinary group provides research, training, and clinical service based on the perspective that culture fundamentally shapes mental health. The division hosts an annual summer training program and conference in Montreal, Quebec. As well, it coordinates the journal Transcultural Psychiatry (tps.sagepub.com/) in association with the Transcultural Psychiatry Section of the World Psychiatric Association (wpa-tps.org), and runs the online Multicultural Mental Health Resource Centre (www. culturementalhealth.com).

Foundation for Psychocultural Research (www.thefpr.org). A private foundation with academic links to UCLA, this nonprofit organization promotes interdisciplinary research on culture, psychology, psychiatry, and neuroscience. The foundation supports regular conferences along with the FPR-UCLA Center for Culture, Brain, and Development (www.cbd.ucla.edu).

International Association for CrossPsychology (www. iaccp.org). The IACCP is the oldest international organization dedicated to the study of cross-cultural psychology. They host biannual conferences, coordinate the Journal of Cross-Cultural Psychology (jcc.sagepub.com/), and have developed the free Online Readings in Psychology and Culture (scholarworks.gvsu.edu/orpc).

Reducing Health Disparities in Asian American $\mathcal{G}$ Pacific Islander Populations (http://erc.msh.org/aapi/index. html). This training resource includes modules on cultural competence, specific Asian American and Pacific Islander cultural groups, traditional medicine, history-taking techniques, adherence, intercultural communication, and epidemiology. Modules include self-assessment quizzes and video clips of interviews with providers and patients. One module, on history taking, excerpts and analyzes material from Anne Fadiman's The Spirit Catches You and You Fall Down (http://erc.msh.org/aapi/tt4.html).

\section{Teaching Suggestions}

The following section describes modules that can be inserted into existing courses. Examples of full syllabi for graduate seminars in culturalpsychology are available at culturalclinicalpsych.org/teaching/syllabi. Unless otherwise specified, references for readings can be found in the previous sections of this guide.

\section{As Part of an Undergraduate Course in Cultural or Cross-Cultural Psychology (1 Week)}

Reading \#1. Chapter on mental health from Heine's (2011) textbook (or equivalent).

Reading \#2. New York Times article about 'Crazy Like Us' and/or Shankar Vedantam's Washington Post series on "Psychiatry's Missing Diagnosis" (both available online).

Activity. The class begins by watching Robert Lemelson's film (or selected clips) from 'Shadows and Illuminations', part of the Afflictions Series. Students then work in groups to identify different accounts of symptoms -e.g., the sufferer, relatives, friends, community, native healer, psychologist, etc. They then consider culture-, mind-, and brain-level influences shaping the person's expression of distress and the ways in which these might interact. Finally, they discuss different treatment efforts across these levels. A discussion involving the entire class then allows the various small groups to share their observations.

\section{As Part of an Introductory Graduate Course in the Prac- tice of Assessment or Therapy (1-2 weeks)}

Reading \#1. Chapters 5 and/or 7 (i.e., assessment and treatment) of Tseng's (2003) guide for clinicians.

Reading \#2. Chapter 4 of the DSM-IV-TR Casebook, on "International Cases" (Spitzer, Gibbon, Skodol, Williams, \& First, 2002).

Activity. Students work in one or more groups, depending on class size. Each group identifies a case example from the DSM-IV-TR casebook that strikes them as unusual or surprising. They first consider culture-, mind-, and brain-level influences shaping the person's expression of distress and the ways in which these might interact. Then, they consider how culturally competent assessment and/or treatment might proceed according to the principles outlined by Tseng.

\section{An Introductory Graduate Lecture on Cultural-Clinical Psychology (1 Week)}

Reading \#1. Ryder, Ban, and Chentsova-Dutton's (2011) paper in Social and Personality Psychology Compass.

Reading \#2. A cultural-clinical case study from anthropology or cultural psychiatry. One example is Tousignant's (1984) paper on sadness in Equador. Other suggestions can be found in the online version of this guide (culturalclinicalpsych.org/teaching/guide).

Activity. Students work in one or more small groups, depending on class size. It is necessary that they have done the readings in advance, especially the case study. Groups brainstormon possible research questions based on the case 
study. They then select a research question and develop ideas for a study that addresses this question. The study should target a particular cultural explanation for a clinical phenomenon -in other words, it should 'unpack culture'. Students should consider (a) the influence of at least two levels of culture-mind-brain, (b) particular cultural scripts that may be operating, and/or (c) looping effects. It is not necessary for a single study to incorporate all of these elements, but they should be a part of the idea-generation process.

\section{A More Advanced Course or Practicum Focusing on the Practice of Cultural-Clinical Psychology (2-4 Weeks)}

Reading \#1. The DSM-5 (American Psychiatric Association, 2013) section on the Cultural Formulation Interview.

Reading \#2. Groleau, Young, and Kirmayer's (2006) paper on the McGill Illness Narrative Interview (see also: http://www.mcgill.ca/tcpsych/research/cmhru/mini)

Activity. Students prepare a case that they can successfully role play -inspiration can be based on clinical and/or personal experience, appropriately fictionalized to protect confidentiality. In class, students are split into groups of three, with one person giving the interview, one person playing a client, and one person observing and taking notes. After the interview, the observer should ask the participants about their experience and then prepare a brief set of comments to share with the whole class. Depending on the amount of time devoted to the exercise, either the CFI, or the MINI, or both interviews can be practiced. This exercise can be spread over several classes, as each student should have the opportunity to be in all three roles.

\section{Short Biographies}

Andrew G. Ryder received his doctorate in psychology (clinical) from the University of British Columbia and currently directs the Culture, Health, and Personality Lab in the
Department of Psychology at Concordia University, where he holds the position of Associate Professor. He is also an adjunct faculty member in the Culture and Mental Health Research Unit at the Sir Mortimer B. Davis -Jewish General Hospital in Montreal. Dr. Ryder's research lies at the intersection of cultural, clinical, and personality psychology. Most of his published work combines at least two of these areas, including papers in Journal of Abnormal Psychology, Harvard Review of Psychiatry, Journal of Affective Disorders, Journal of Personality and Social Psychology, and Journal of Personality Disorders. Current research focuses on: (a) the intersection of cultural and personality variables in shaping depressive symptom presentation in China and South Korea; and (b) acculturation and adaptation in complex multicultural societies. His work is supported by a New Investigator Award from the Canadian Institutes for Health Research (CIHR) and grants from CIHR and the Fonds de la recherche en santé du Québec.

Yulia E. Chentsova-Dutton received her master's degree (clinical science and psychopathology) from the University of Minnesota and her doctoral degree (affective science) from Stanford University. She holds the position of assistant professor in the Department of Psychology at Georgetown University in Washington, D.C., where she directs the Culture and Emotion Lab. Her research spans cultural psychology, emotions, and mental health, and her publications include papers in the Journal of Abnormal Psychology, Journal of Personality and Social Psychology, and Cultural Diversity and Ethnic Minority Psychology. Her specific research interests include the cultural shaping of: (a) emotions, including conceptions and functions of emotions, emotional reactivity, and interoception; and (b) social support, including advice giving and support networks. Her work is supported by the Social Psychology Program of the National Science Foundation. 